Administrative Issues Journal: Connecting Education, Practice, and Research, Summer 2019 Vol. 9, No. 1: 19-34. DOI: 10.5929/9.1.3

\title{
The accounting doctoral shortage: Accounting faculty opinions on hiring JD-CPAs as accounting educators
}

\author{
Ramsey L. Cardwell, M.Sc. \\ University of North Carolina at Greensboro \\ Ronald O. Cardwell, J.D. \\ Guilford College \\ John T. Norris, Ph.D. \\ University of the Incarnate Word \\ Michael P. Forrest, J.D. \\ University of the Incarnate Word
}

\begin{abstract}
Objectives: Prior studies have noted that the number of PhDs in accounting are far below the number needed to meet program hiring needs. This paper reviews how the JD-CPA alternative credential is viewed by three academic accreditation bodies (SACS, ACBSP, and AACSB), the American Bar Association (ABA), and current accounting faculty at SACS-accredited institutions of higher education. Methods: An online survey was distributed to accounting educators at 439 institutions accredited by SACS, with 248 complete responses received. Individual demographics and institutional information were summarized statistically. Responses to two questions assessing inclination to hire an otherwise-qualified JD-CPA candidate using a 5-point Likert scale were analyzed by multiple regression with individual and institutional variables as predictors. Results: The study found that JD-CPA accounting educators are widely present in accounting faculties. Responses to the opinion questions indicated a substantial willingness to hire JD-CPAs, albeit with significant differences based on institution type, faculty rank, and possession of a PhD. Conclusion: This study demonstrates general willingness among current accounting faculty to consider JD-CPAs for tenure-track accounting faculty positions while still expressing a preference for candidates with a PhD and with notable reservations from certain demographic segments of the accounting academe.
\end{abstract}

Keywords: Accounting Educator, Ph.D. Shortage, Doctoral Shortage

\footnotetext{
$\mathrm{F}$
}

or decades, business education scholars have discussed the shortage of PhDs in accounting. Shipley and Engle (1982) rang the warning bell on this issue, citing surveys from 1974 (Stone, 1974) and 1980-81 by the American Assembly of Collegiate Schools in Business (now the Association to Advance Collegiate Schools of Business; henceforth AACSB), which showed a significant shortage of accounting PhD applicants for academic positions. Additional articles in professional and academic journals have since corroborated the shortage (Behn et al., 2012; Beyer et al., 2010; Boyle et al., 2015; Hermanson, 2008; Prescott et al., 2017; Prather-Kinsey et al., 2018). And despite more recent efforts by organizations such as the American Institute of Certified Public Accountants (AICPA) and the Financial Accounting Standards Board (FASB) to ameliorate the situation through funding for accounting doctoral study and bridge programs for holders of PhDs in other fields, a shortage of doctorally-qualified

CARDWELL, CARDWELL, NORRIS, \& FORREST / DOI: 10.5929/9.1.3 
accounting faculty persists 40 years later (Boyle et al., 2015; Prescott et al., 2017). The purpose of this study is to explore accounting faculty attitudes on, and accreditation standards limitations to, the hiring of individuals holding a doctorate in law (the terminal degree of Juris Doctor [JD]) combined with professional certification in accounting (CPA or other designations) as a means of ameliorating the longstanding shortage of PhDs in accounting in the academic marketplace.

Scholarship abounds documenting the increasing difficulty accounting programs have in filling open faculty positions in accounting (Behn et al., 2012; Beyer et al., 2010; Hermanson, 2008). The AICPA Pathways Report on Accounting in Higher Education (Behn et al., 2012) determined that this shortage will continue due to older full-time tenured faculty members (the average age being 58 ) nearing retirement combined with a constricted supply of incoming PhD accounting students. Using statistics published by the AICPA and the American Accounting Association (AAA), Ruff et al. (2009) estimated that accounting faculty members were projected to retire at a rate of 500 to 700 (up to 6\%) per year for the next decade. However, even with the development of new doctoral programs in recent years, the total number of universities in the United States granting accounting doctorates stands at only 82 (AAA, 2017). According to the National Science Foundation (2015), the number of doctorates in accounting awarded annually between 2005 and 2015 has ranged from a low of 130 in 2005 to a high of 196 in 2014 . Even with this apparent increase in accounting PhDs, the number of students graduating in recent years is still far from sufficient to fill the anticipated vacancies left by retiring faculty members.

A response to this problem has been the practice of hiring from alternative doctoral programs, with recent Doctor of Business Administration (DBA) graduates being hired into tenure-track positions at several institutions (The Pathways Commission, 2015). Nonetheless, many universities and colleges will still be forced to find accounting faculty outside of traditional doctoral programs. For example, Showalter and Bodtke (2016) outlined the use of Professionally Oriented Faculty (POF) through the implementation of the Pathways Commission Professionally Oriented Faculty Integration Principles (2012).

In general, large state research institutions can find PhD-qualified faculty to fulfill their missions. Bishop et al. (2016) reported, however, that $96 \%$ of smaller accredited schools say the lack of qualified accounting faculty is detrimental to their programs. As Schneider and Sheikh (2012) noted, there are only two options for solving the shortage: reducing the demand or increasing the supply. Schneider and Sheikh focused on the use of non-tenure-track (NTT) faculty, which they define as including any faculty member holding a rank other than assistant professor, associate professor, or full professor, as a possible approach to increase supply. Their findings revealed that $28.7 \%$ of faculty members at prestigious accounting programs were, in fact, NTT. Regardless of the availability of NTTs, the shortage of accounting PhDs forces institutions to examine alternatives to full-time tenure-track faculty. Hunt and Jones (2015) surveyed 851 chairs of accounting departments to gauge how they staffed courses when unable to hire tenure-track faculty. They found that 210 of the 237 respondents had attempted to hire new faculty, but 57 of those were unable to fill all vacancies. Some of the accounting faculty members with non-accounting PhDs are graduates of one of the AACSB Bridge Programs.

\section{Accreditation Standards}

There are three higher education accreditation bodies and one professional organization with standards that are pertinent to the discussion of JD-CPAs as accounting educators. This section summarizes the relevant standards from each organization.

\section{Southern Association of Colleges and Schools (SACS)}

SACS accredits higher education institutions in 11 southern states and US-affiliated schools in Latin 
America. It determines qualified faculty based on the highest degree earned in a particular discipline, along with other professional competence, licensures, or certifications (SACS, 2012, p. 30). According to their faculty credential guidelines, a doctorate or master's degree in the discipline taught, or master's from another field with at least 18 semester hours in the discipline taught, is required to teach undergraduate courses (SACS, 2006, p. 1). An earned doctorate or terminal degree in the discipline or a related discipline is required for teaching graduate courses (p. 1). For comparison, the standard content in JD coursework includes the study of contracts, legal research and writing, the Uniform Commercial Code, taxation, ethics, business entities, evidence, and court procedures overlapping with the subject content in business law, tax, forensics, business communications, and ethics accounting courses. Thus, under SACS criteria, a JD degree is a closely-related terminal degree, qualifying degree holders to teach accounting courses. Accordingly, JD-CPA credentials can be used to satisfy SACS Standard 3.5.4, which requires terminal degree faculty to teach a substantial number of accounting baccalaureate courses.

\section{Accreditation Council for Business Schools and Programs (ACBSP)}

Like SACS, ACBSP is another accrediting organization, albeit focused specifically on business programs, emphasizing innovative teaching and effective delivery of business education programs. In their standards and guidelines, ACBSP (2016) considers faculty academically qualified if the faculty member has completed 15 graduate hours in the teaching discipline and holds either a doctorate in business, a professional certification, or five or more years of professional and management experience in the area of teaching responsibility. Ultimately, ACBSP states that faculty holding JD degrees are academically qualified to teach "business law, legal environment of business or other areas with predominantly legal content” (ACBSP, p. 61).

\section{The Association to Advance Collegiate Schools of Business (AACSB)}

AACSB is dedicated to improving business education to meet the needs of business practice. AACSB not only accredits schools with business programs but also has a separate accreditation for institutions granting degrees in accounting. In evaluating an institution, AACSB categorizes faculty members as either Scholarly Academics or Practice Academics, describing the categories as follows:

Scholarly Academics (SA) sustain currency and relevance through scholarship and related activities. Normally, SA status is granted to... faculty members who earned their research doctorates within the last five years prior to the review dates.

Practice Academics (PA) sustain currency and relevance through professional engagement, interaction, and relevant activities. Normally, PA status applies to faculty members who augment their initial preparation as academic scholars with development and engagement activities that involve substantive linkages to practice, consulting, other forms of professional engagement, etc., based on the faculty members' earlier work as an SA faculty member. (AACSB, 2017b, p. 45)

Though both the SA and PA categories apply to faculty holding doctoral degrees, the criteria for SA indicates a "research doctorate" (AACSB, 2017). Presumably, a legal education comprising up to 90 hours of instruction in the classroom, without a dissertation, would not fit so easily under this descriptor. Nevertheless, PAs also hold doctoral degrees-this would include a Juris Doctorate. Thus, if the JD faculty were trained in academic research methodology, such a credential should put him or her on par with a colleague holding a PhD in accounting.

\section{American Bar Association (ABA)}

In its 2012-2013 Standards and Rules of Procedure for Approval of Law Schools, the ABA advised that the

CARDWELL, CARDWELL, NORRIS, \& FORREST / DOI: 10.5929/9.1.3 
two degrees of JD and PhD "shall be considered as equivalent degrees for educational employment purposes" (p. 145). The ABA justified its position by numerical equivalency, in that the JD requires 84-90 post-baccalaureate semester hours compared with the 60 semester hours of PhD study spent in the classroom as well as the hours writing one's dissertation.

Within the context of accreditation standards, the question of qualifications in the accounting classroom depends on either academic coursework, professional experience, or licensure. However, notwithstanding the differences of the accreditation standards of SACS, AACSB, and ACBSP, all of those accrediting bodies permit the JD degree to be counted as a doctorate in compliance with the standards of each respective accreditation.

\section{Availability of JD-CPAs}

In order to argue hiring JD-CPAs as credentialed accounting educators as a viable solution to the accounting PhD shortage, it is necessary that there be a sufficient number of JD-CPAs to fill an appreciable number of accounting faculty vacancies. As of 2015, there were 1,300,705 licensed attorneys (predominately with JD degrees) in the United States (ABA, 2015). According to the American Academy of Attorney-CPAs, there are currently more than 1,000 attorney-CPA members (AAA-CPA, 2017). Therefore, hiring committees in accounting programs can attract additional applicants by expanding their scope to include members of AAA-CPA. This additional supply of JD-CPAs offers further support for JD-CPAs as a viable equivalent to accounting PhD holders.

\section{Research Questions}

Based on our review of the literature and our experience as accounting educators, we developed the following primary research questions to guide the survey development:

Research Question \#1: To what extent are a law doctorate (JD degree) and a CPA license, in combination (JD-CPA), perceived as acceptable credentials for employment as an accounting educator by those involved in accounting education and hiring at colleges and universities accredited by SACS?

We expect a moderate degree of acceptance of JD-CPA credentials given their permissibility under the SACS accreditation standards as a terminal degree for the purpose of accrediting accounting programs. However, we do not expect to find widespread acceptance of JD-CPA credentials due to, among other factors, the apparent ambiguity of the accreditation standards concerning the acceptability of JD-CPA credentials, as well as, an enduring preference for the accounting PhD credential.

Research Question \#2: To what extent does the perceived acceptability of JD-CPA credentials for employment as an accounting educator vary by institutional characteristics (e.g., research-oriented vs. teaching-oriented, graduate degree-granting vs. undergraduate) and personal characteristics (e.g., degree held, age)?

We expect significantly less acceptance of JD-CPA credentials among survey participants from selfdescribed research-oriented institutions, given the closer alignment of a research mission with the emphasis placed on research that characterizes PhD programs. Additionally, we expect holders of a PhD to be less accepting of JD-CPA credentials, and, also, for acceptance of JD-CPAs to decrease with age.

\section{Method}

To assess opinions of current accounting faculty members and deans concerning the hiring of JD-CPAs for full-time accounting educator positions, we constructed a survey, comprising 28 questions, that builds upon prior literature (e.g., Boyle et al., 2015; Bishop et al., 2016) examining the shortage of PhDs in 
accounting. The survey included demographic questions and questions about the hiring of JD-CPAs for accounting faculty positions. One set of questions elicited objective information concerning the presence of JD-CPAs in the respondents' departments, whereas another set of questions concerned respondents' subjective personal opinions on the hiring of JD-CPAs. The departmental-related questions asked the number of JD-CPAs currently employed in the respondent's department, the reasons JD-CPAs have been hired in the respondent's department and the positions for which they were hired, the eligibility of JDCPAs for tenure, and the courses taught by JD-CPA respondents. The remaining questions asked about findings from accreditation reviews (i.e., SACS, ACBSP, AACSB).

\section{Survey Population}

The survey was distributed via email to accounting faculty members at 439 institutions from the 11 states in the operational area served by SACS listed in Hasselback's Directory of Accounting Faculty (Hasselback, 2015). SACS accredits approximately 530 four-year degree schools in the 11 states within its jurisdiction (SACS, 2016). We acquired additional email addresses for academic deans (Dean of the College, Dean of the School of Business, etc.) from the websites of the institutions listed in the SACS Membership Directory. The target population, thus, included a broad array of the accounting academic faculty and administrative hiring agents with knowledge of the accounting faculty marketplace and the hiring needs of the educational institution.

Excluding undeliverable invitations, the survey response rate was $14.4 \%(n=267)$, somewhat higher than response rates to previous surveys of accounting faculty: 13.0\% (Bailey et al., 2008), 12.4\% (Boyle et al., 2015), and $11.7 \%$ (Blanthorne et al., 2007). Of the total survey respondents, 19 were excluded from analysis due to early termination $(n=10)$ or not meeting eligibility criteria $(n=9)$. Subsequent analyses are, thus, based on 248 respondents. Descriptive statistics of this sample are provided in Table 1 following the format of Boyle et al. (2015).

\section{Results}

\section{Demographics}

As shown in Table 1, the survey respondents included 148 professors, 31 lecturer/instructors, 39 chairs, 10 program directors, and 20 deans. Those classified as chairs, program directors, or deans were not included in the count of professors and lecturers. Concerning gender, $41 \%$ of respondents identified as female and $55 \%$ as male. Sixty percent of respondents are older than 55 , and $85 \%$ identified racially as white/European American. Sixty-five percent of respondents hold a PhD, while an additional $17 \%$ hold a doctorate other than a PhD (e.g., DBA or Ed.D.). Eighty percent have more than 10 years of experience in higher education. Seventy-eight percent hold CPA certification and $26 \%$ hold other accounting certifications (e.g., CMA, CIA), mostly in conjunction with CPA certification. Eighty-three percent reported having been involved in the faculty hiring process within the past five years.

To assess the sample representativeness, we compared proportions of genders and academic positions in the sample to population values from Boyle et al. (2015) using chi-square tests for equality of proportions. We found no significant difference (i.e., $p>.05$ ) between the sample and the population for the proportion of associate professors ( $27.8 \%$ sample, $23.3 \%$ population), chairs ( $15.7 \%$ sample, $12.1 \%$ population), or deans (8.1\% sample, $8.9 \%$ population). The sample contained significantly larger proportions of lecturers (including all non-tenure track faculty positions such as instructor; $12.5 \%$ sample, $8.8 \%$ population), females (41.1\% sample, 35\% population), and respondents from doctorate-granting institutions $(42.7 \%$ sample, $27 \%$ population). Also, the sample contained significantly smaller proportions of assistant professors (13.7\% sample, $22.9 \%$ population) and full professors (18.1\% sample, $23.3 \%$ population). 
Table 1. Survey sample descriptive statistics

\begin{tabular}{ll}
\hline Individual Characteristics & \\
Participant Type & \\
Professor (Assistant, Associate, Full) & 148 \\
Instructor / Lecturer & 31 \\
Chair & 39 \\
$\quad$ Program Director & 10 \\
$\quad$ Dean & 20 \\
Total & 248 \\
Gender & \\
& $41 \%$ female \\
Age & $55 \%$ male \\
Race & $60 \%$ older than 55 \\
Highest Degree Received & $85 \%$ white \\
Years of Experience in Academia & $65 \%$ hold a PhD \\
CPA Certification & $17 \%$ hold non-PhD doctorate \\
Other Accounting Certification & $80 \%$ have more than 10 years of experience \\
Faculty Hiring Participation & $78 \%$ hold CPA certification \\
& $26 \%$ hold other certifications \\
Institutional Characteristics & $83 \%$ involved in hiring in past 5 years \\
Research or Teaching Orientation & \\
& \\
Highest Degree Offered & $33 \%$ from research-oriented institutions \\
& $13 \%$ from teaching-oriented institutions \\
& $54 \%$ from balanced research/teaching \\
& $43 \%$ offer doctorate \\
& $45 \%$ offer masters \\
& $12 \%$ offer bachelors \\
\hline & \\
&
\end{tabular}

Concerning the academic institutions of the survey respondents, 33\% reported working at a researchoriented institution (henceforth research schools), 13\% at a teaching-oriented institution with no requirement for faculty research (henceforth teaching schools), and $54 \%$ at teaching-oriented institutions that require some degree of peer-reviewed publication from the faculty (henceforth balanced schools). Regarding the highest degree offered at the institution, $43 \%$ of respondents reported working at doctorate-granting institutions (henceforth doctoral schools), 45\% at master's degree-granting institutions (henceforth master's schools), and $12 \%$ at bachelor's-granting institutions (henceforth bachelor's schools). There was a significant association between the granting of doctorates and classification as a research-oriented institution $\left(\chi^{2}(2, N=217)=44.98, p<.001\right)$. As for programmatic accreditation, 183 respondents (69\%) are from AACSB-accredited institutions, and 31 (12\%) are from ACBSP-accredited institutions. All respondents are affiliated with SACS-accredited institutions by design.

\section{Analysis of Institutional Variables}

As explained in the Method section, some survey questions pertained to information about the departments in general, as opposed to the individual respondents. This included the hiring and tenure promotion of JD-CPAs and courses taught by JD-CPAs. Additionally, respondents were asked to report the 
number of JD-CPAs currently on the accounting faculty at their institutions. Representing nearly half of the sample, 114 respondents (46\%) reported no JD-CPAs currently working in their accounting programs. One hundred ten respondents (44\%) reported one to three JD-CPAs, 17 respondents (7\%) reported four to six JD-CPAs, and seven respondents (3\%) reported seven or more JD-CPAs (Figure 1).

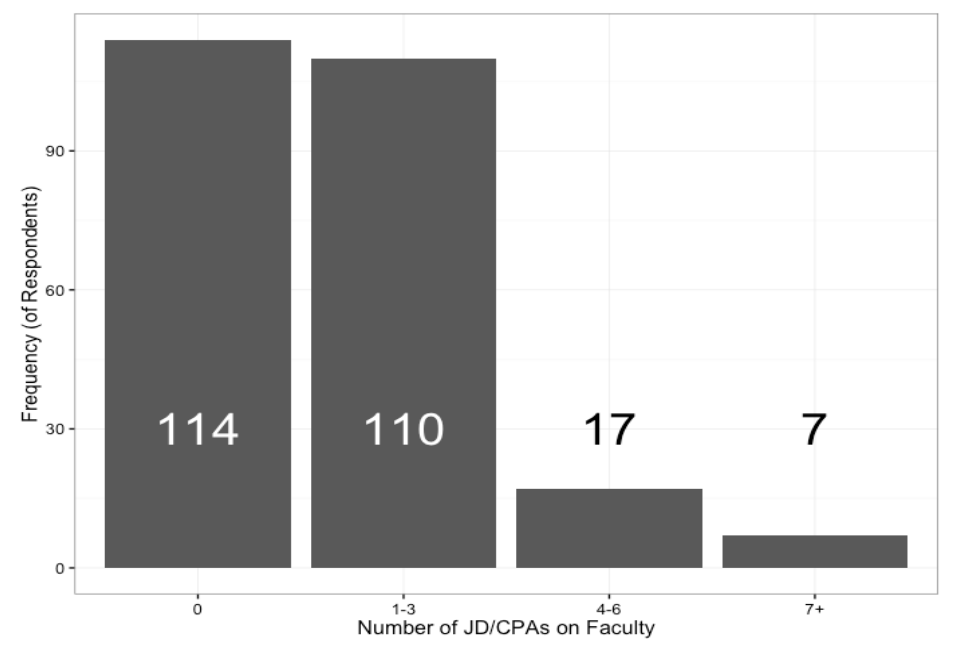

Figure 1. Histogram of number of JD-CPAs reported at institution of each respondent

Hiring and promotion of JD-CPAs. When asked to select the reasons for hiring a JD-CPA accounting educator (if one had been hired in the past five years), 37 respondents selected "I do not know," 30 selected "Educational and/or work experience in law adds to students' educational experience," 16 selected "PhD in accounting was not in applicant pool," 11 selected "Market compensation for JD-CPA less than PhD in accounting," and 9 selected "For the accounting department to comply with SACS Standard 3.5.4 regarding coverage by terminal degree faculty." Multiple responses were permitted for this question.

In response to the question concerning reasons for hiring JD-CPA faculty, 26 respondents provided writein responses. Of these, 12 were related to teaching Tax and/or Business Law (e.g., "needed someone who could teach both business law and tax"). Four responses indicated that the candidate's specific credentials were not important, as they were hired for a non-tenure-track or teaching-focused position (e.g., "Hiring in non-tenure track position, so $\mathrm{PhD}$ and research not required"). An additional three responses expressed that the JD-CPA candidate happened to be the most qualified candidate (e.g., "He is the most qualified person in the pool"). Of the 101 respondents reporting JD-CPAs being hired in their departments in the past five years, most indicated JD-CPAs were hired for typically non-tenure track positions including Instructor ( $n=28)$, Adjunct $(n=28)$, Lecturer $(n=26)$, and Part-Time $(n=14)$. A lesser number were hired for typically tenure-track positions: Assistant Professor $(n=23)$, Tenure-Track Faculty $(n=10)$, Professional Practice Professor $(n=9)$, and Associate Professor $(n=6)$.

Table 2. Results of one-way ANOVA for number of JD-CPAs by institutional orientation

\begin{tabular}{lccccc}
\hline \multicolumn{1}{c}{ Source } & $d f$ & $S S$ & $M S$ & $F$ & p-value \\
\hline Orientation & 2 & 10.4 & 5.224 & 3.642 & $0.0277^{*}$ \\
Residuals & 236 & 338.5 & 1.434 & & \\
\hline
\end{tabular}

We explored the relationship between school orientation and the number of JD-CPA faculty members using a one-way ANOVA after removing nine outliers (Table 2). There was a significant effect of school 
orientation on the number of JD-CPA faculty $(F(2,236)=3.62, p=.028)$. Post hoc Tukey HSD comparisons (Tukey, 1949) indicated that the mean number of JD-CPAs at research schools $(M=1.24, S D=1.39)$ was significantly greater than at balanced schools $(M=0.81, S D=1.10)$, but not significantly different from the number at teaching schools $(M=0.73, S D=1.11)$. A chi-square test of independence corroborated the ANOVA results. Comparing only balanced and research schools on a binary variable indicating presence of JD-CPA faculty members (i.e., $1=$ at least one JD-CPA, $0=$ no JD-CPA), the data showed a significant association between school orientation and the presence of JD-CPA faculty members, (Yates continuity-corrected $\left.\chi^{2}(1, N=217)=5.27, p=.022\right)$. A significantly higher proportion of respondents from research schools ( 54 of 82 respondents, or $66 \%$ ) reported JD-CPAs on the accounting faculty, as compared to balanced schools (66 of 135 respondents, or $49 \%$ ).

Concerning the role JD-CPA candidates were hired to fill in the department, a significantly larger proportion of JD-CPAs hired at the research institutions represented by the survey were hired for nontenure track positions compared to non-research schools $\left(\chi^{2}=13.4, p<.001\right)$. Despite the significant association between school orientation and highest degree offered, there were no significant differences in the number of JD-CPAs reported based on highest degree offered at the institution both before and after removing outliers. Looking at the courses JD-CPA faculty teach, a majority of the 26 JD-CPA survey respondents reported teaching Tax (20) and Financial Accounting (14), while many reported teaching Cost Accounting (10), and Business Law (9). Relatively few respondents reported teaching other accounting topics. Additionally, there was no significant association between research orientation and JD-CPA faculty teaching only Tax and Law courses (Yates-corrected $\chi^{2}=2.39, p=.12$ ), which might be expected if research schools hire JD-CPAs to fulfill a specific purpose.

Table 3. Results of logistic regression predicting tenure eligibility of JD-CPA faculty

\begin{tabular}{lcccc}
\hline & Exp (B) & Sig. $(p)$ & \multicolumn{2}{c}{$95 \% \mathrm{Cl}$} \\
\cline { 4 - 5 } Variable & OR & & Lower & Upper \\
\hline & & & & \\
\hline Institution Type & & $<.001$ & 0.06 & 0.24 \\
Research & 0.12 & .80 & 0.34 & 2.89 \\
Teaching & 0.89 &
\end{tabular}

Note. McFadden's pseudo- $R^{2}=.16$. OR=odds ratio; $\mathrm{Cl}=$ confidence interval.

When asked if otherwise-qualified JD-CPAs would be eligible for tenure in their department, 101 respondents (41\%) said "Yes," 99 respondents (40\%) said "No," and 48 respondents (19\%) said, "I do not know." A logistic regression model with Tenure Eligibility (Yes/No) as the outcome variable and institutional orientation (Research /Teaching /Balanced) as the predictor (Table 3) was obtained by subjecting a more complex model to bidirectional stepwise regression using the Akaike information criteria (AIC; Akaike, 1974). The coefficient of the research dummy variable can be interpreted as indicating that the odds of a JD-CPA being eligible for tenure (as opposed to non-tenure track) at a balanced school are approximately eight times greater than the odds at a research school (95\% Cl: 4 to 17 times greater). However, the odds of tenure eligibility at a teaching school are not significantly different from the odds at a balanced school.

"Findings" from SACS Accreditation Reviews. When asked if their institution had experienced a "finding" (an issue requiring explanation or corrective actions) relating to their JD-CPA accounting faculty during a SACS accreditation review, the results indicated that there were a small number of findings; $3.88 \%(n=10)$ responded with a "Yes," with the remaining responses indicating no related findings at their colleges or knowledge thereof. Further information concerning the nature and resolution of the findings was not 
solicited. Given that all (288) of the survey participants were at SACS colleges and universities, the small number of JD-CPA related findings by SACS indicates that there does not appear to be a substantial sentiment opposing JD-CPAs on accounting faculties in the states covered by SACS. In general, the survey results indicate a relatively small number of SACS accreditation findings relating to JD-CPA faculty.

\section{Analysis of Individual Variables}

Three survey questions asked for respondents' personal opinions concerning the hiring of JD-CPAs in accounting departments. One question asked how respondents would view a JD-CPA job candidate in comparison to an otherwise equally qualified holder of a PhD in accounting. The second question asked respondents to what extent they would recommend the hiring of an otherwise qualified JD-CPA candidate for a tenure-track position in their department. The third question asked respondents if they think the hiring of JD-CPAs should be recommended as one measure to counteract the shortage of PhDs in accounting.

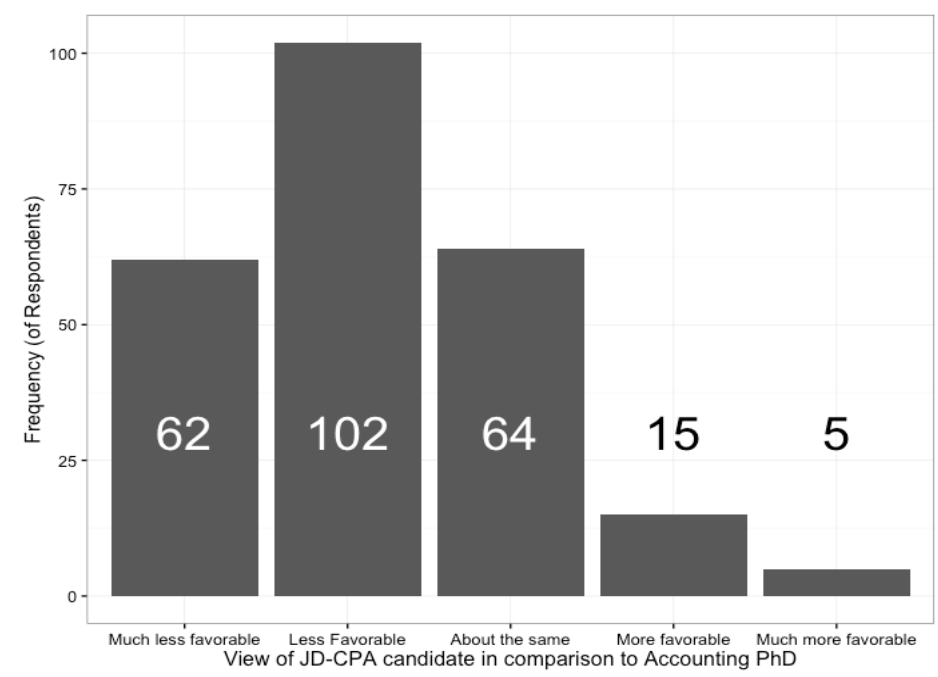

Figure 2. Frequency of responses to the question concerning view of JD-CPA candidate

View of JD-CPA job candidates. The five response options to this question ranged from "JD-CPA much less favorable" to "JD-CPA much more favorable." Overall, the JD-CPA candidate was viewed as less favorable than the PhD-holding candidate (Figure 2), with the median and most frequent response as "Less favorable." Only 20 respondents would consider the JD-CPA candidate "more favorable" or "much more favorable," whereas 164 respondents would view the JD-CPA candidate as "less favorable" or "much less favorable." The remaining 64 respondents would view the two candidates equally. Following the analysis approach of Boyle et al. (2015), we fit a multiple regression model (Table 4) with various individual and institutional characteristics predicting response to the survey question (Adjusted- $R^{2}=.20$, $F(21,217)=3.91, p<.001)$. For use in the regression model, the response options were assigned numerical values from 1 to 5 ( 1 = "JD-CPA much less favorable," 5 = "JD-CPA much more favorable"). The results indicate which factors contribute to a relatively more or less favorable view of JD-CPAs in an ordinal sense. 
Table 4. Results of multiple regression models predicting responses to two survey questions

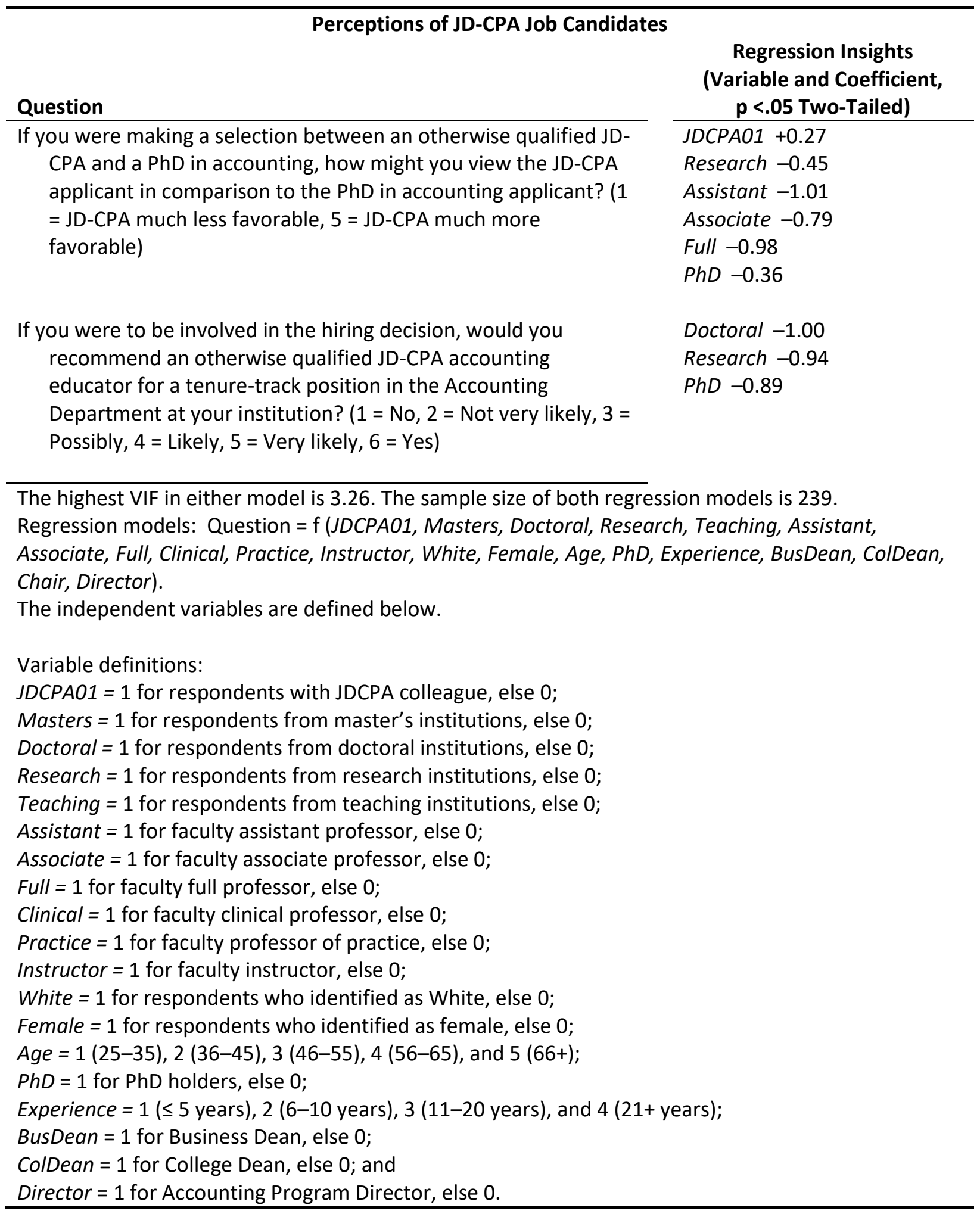

CARDWELL, CARDWELL, NORRIS, \& FORREST / DOI: 10.5929/9.1.3 
Regarding one's view of a hypothetical JD-CPA candidate compared to a PhD applicant, the regression results indicate that when controlling for all other individual and institutional characteristics, respondents who currently work in a department with a JD-CPA on the faculty would view the JD-CPA candidate significantly more favorably than respondents who do not work with a JD-CPA colleague. Conversely, respondents from research schools view the JD-CPA candidate significantly less favorably compared to respondents from balanced schools (balanced schools were the reference group of the Institution Type variable). Likewise, assistant, associate, and full professors all viewed the JD-CPA candidate significantly less favorably in comparison to lecturers (lecturers were the reference group of the Academic Rank variable). And finally, respondents with a PhD viewed the JD-CPA candidate significantly less favorably than respondents with degrees other than a PhD.

Recommending JD-CPA candidate for tenure-track position. When asked how likely they would be to recommend hiring an otherwise qualified JD-CPA candidate, the most common response was "Yes" ( $n=61)$ followed by "No" ( $n=53)$, with the remaining respondents distributed among the middle response options (Figure 3). We fit a multiple regression model (Table 4) with various individual and institutional characteristics as predictors (Adjusted- $R^{2}=.24, F(21,217)=4.58, p<.001$ ). For use in the regression model, the response options were assigned numerical values from 1 to $6(1=$ "No," $6=$ "Yes" $)$. The results indicate that, when controlling for all other variables, respondents from doctoral schools would be significantly less likely to recommend an otherwise qualified JD-CPA candidate (compared to undergraduate-only schools, the reference group). Additionally, respondents from research schools would also be significantly less likely to recommend a JD-CPA candidate (compared to balanced schools). And finally, PhD holders would be significantly less likely to recommend a JD-CPA candidate.

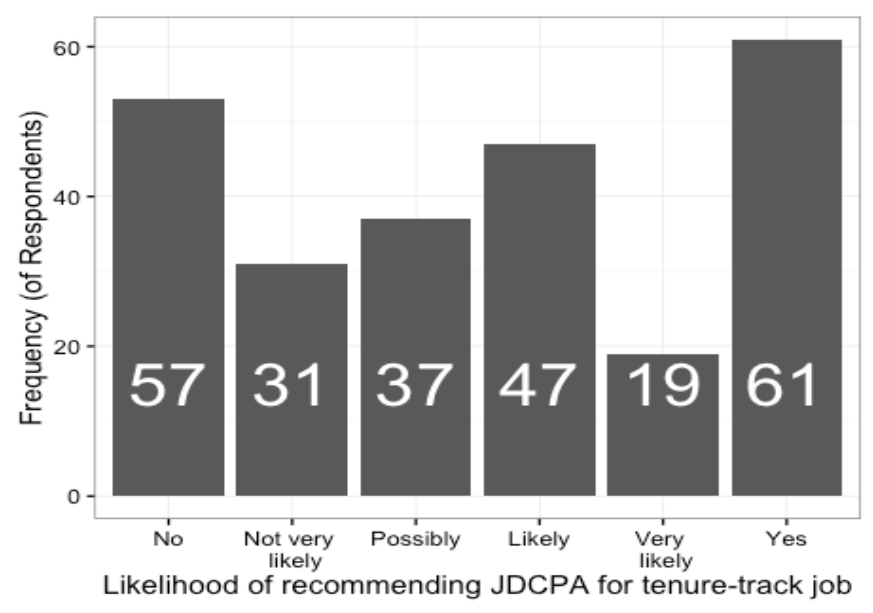

Figure 3. Frequency of responses to the question concerning likelihood of hiring JD-CPA for tenure-track position

View on hiring JD-CPAs as solution to accounting PhD shortage. The final survey question asked if respondents felt the hiring of JD-CPAs for accounting faculty positions should be recommended to mitigate the continuing shortage of PhDs in accounting. There were three response options: "No" ( $n=62)$, a qualified "Yes" endorsing the limited hiring of JD-CPAs ( $n=68)$, and "Yes" ( $n=86)$. The unqualified "Yes," stating that the hiring of JD-CPAs should be increased as much as accreditation standards will allow, was the most frequent response. An additional 30 respondents chose "Other" and provided write-in responses. Therein, two respondents emphasized that a qualified JD-CPA candidate should be considered as viable as a PhD applicant. Another two respondents indicated that a JD-CPA applicant would need an additional credential (e.g., LLM) to be considered at their institution. Two respondents expressed that they do not 
believe there is a shortage of accounting PhDs. A further two respondents expressed doubt that a JD-CPA candidate could meet the research requirements of their institution. Five respondents said that JD-CPAs should be considered only for non-tenure track positions. And finally, eight respondents endorsed the hiring of JD-CPAs for narrowly-defined roles such as teaching Tax or Business Law.

\section{Discussion}

This section addresses each research question in light of the preceding survey results.

\section{Research Question \#1}

All survey respondents ( $n=266$ ) work in schools with SACS accreditation. Respondents holding a JD as their highest degree represented $6.08 \%(n=16)$, while $10.08 \%$ of respondents $(n=26)$ responded to the question addressed to JD-CPA faculty members, indicating that between $6 \%$ and $10 \%$ of our sample are JD-CPA accounting educators. While the JD degree is represented, the degree representation is far less than the $\mathrm{PhD}$, which represents $65.40 \%$ of the respondents. Furthermore, $54 \%$ of respondents $(n=134)$ reported at least one JD-CPA on the faculty in their department. Thus, notwithstanding some negative opinions of JDCPA credentials in accounting academia, JD-CPAs have a wide presence on accounting faculties, even at institutions with AACSB programmatic accreditation. And despite the widespread presence of JD-CPAs, very few respondents reported SACS accreditation findings related to JD-CPA faculty, indicating general compatibility of JD-CPA faculty members with the SACS standards.

Only $2.33 \%$ of respondents reported that, to their knowledge, there had been a SACS accreditation review finding related to the terminal degree status of JD-CPA faculty under SACS Standard 3.5.4. Given that 58\% of respondents $(n=134)$ reported at least one JD-CPA on the faculty at their institution, the relatively small number of reported findings related to JD-CPA credentials would indicate that the presence of JD-CPAs is typically not seen as a source of noncompliance with SACS Standard 3.5.4. Additionally, a reported finding does not mean that the institution was ultimately sanctioned for noncompliance. It is likely that the findings were resolved without sanction. However, we did not elicit further details on the outcome of the SACS findings, and, thus, we cannot make any claims about their resolution.

When asked why JD-CPAs had been hired at their institutions, there were two general themes among the responses of those who reported reasons. The more common theme, revolving around content areas, was that JD-CPAs' expertise in tax and law was needed in the department and would be beneficial to students. The second theme, related to practical concerns, was that JD-CPAs can be appealing candidates for full-time positions when PhDs are not available or are unaffordable (due to the economics of a shortage in supply driving up compensation for PhDs in Accounting), or that the nature of credentials are not important when hiring for part-time positions. A small number of respondents reported that meeting SACS Standard 3.5.4 was a reason their institution hired a JD-CPA. As far as the positions for which JDCPAs were hired, a majority of responses to this question indicated that JD-CPAs were hired for nontenure-track, often part-time, positions. However, $40 \%$ of respondents indicated that newly hired JD-CPAs would be hypothetically eligible for tenure track at their institutions.

The data show $62.5 \%$ of survey respondents stated that they would recommend JD-CPA candidates for hiring within their accreditation standards to ameliorate the shortage of PhDs in accounting. Furthermore, approximately half of respondents indicated that they would likely recommend hiring an otherwise qualified JD-CPA candidate for a tenure-track position. However, the majority of respondents would still prefer a candidate with a PhD in accounting over a JD-CPA candidate.

Taken together, these results suggest that JD-CPAs occupy two general roles at SACS-accredited

CARDWELL, CARDWELL, NORRIS, \& FORREST / DOI: 10.5929/9.1.3 
institutions. The more prevalent and less controversial role is that of an adjunct or instructor/lecturer who primarily teaches tax and law courses. The other is that of a full-time, potentially tenure-track, faculty member who teaches various accounting courses. While there exists more resistance to the latter role, many also recognize that the hiring of JD-CPAs as full-time accounting educators is both permissible under SACS accreditation standards and helpful for institutions to achieve compliance with Standard 3.5.4. There is also recognition of JD-CPAs as a viable alternative to PhDs during the accounting doctoral shortage. However, acceptance of JD-CPA credentials can vary depending on individual and institutional characteristics.

\section{Research Question \#2}

The results pertaining to this research question were not as straightforward. While respondents from teaching and balanced schools with primarily undergraduate programs in accounting are considerably more likely to recommend hiring JD-CPAs, respondents from research schools actually reported significantly more JD-CPA educators at their institutions compared to teaching/balanced schools. There is, thus, a nuanced situation wherein research school respondents are less likely to recommend hiring or giving tenure to JD-CPA candidates, even though on average the research schools employ more JD-CPAs. While also potentially due to differences in faculty size between research and non-research schools, we postulated this apparent inconsistency might be explained by differences in the nature of classes taught by JD-CPA educators at the different institution types. However, we did not find a significant association between institution type and the teaching of only Law/Tax. We did, however, find that a significantly larger proportion of JD-CPAs hired at research schools are filling non-tenure track positions, providing some support for the idea that research schools are currently using JD-CPAs as a supplement to PhDs in accounting.

Our expectations were, thus, partially confirmed. The results indicate that a $\mathrm{PhD}$ is viewed considerably more favorably for hiring recommendations by respondents working at research-intensive programs at the graduate level. And while on average more JD-CPAs are employed at research institutions, they tend to hold non-tenure track positions that presumably do not require the research output characteristic of tenure-track positions at research schools. Respondents from teaching schools and balanced schools, which place less emphasis on research publication, were more likely to recommend hiring a JD-CPA. When controlling for other variables, assistant, associate, and full professors were all significantly lower than lecturers in their reported likelihood of recommending hiring a JD-CPA candidate. Additionally, respondents who themselves hold a PhD or work at research schools were significantly less likely to recommend hiring a JD-CPA candidate and expressed a stronger preference for a PhD candidate.

The data showed no significant effect of demographic variables (race, gender, age, or job experience) on the view of JD-CPA candidates in relation to PhD in accounting candidates. This result could reflect a true lack of relationship between these variables and the view of JD-CPAs or may be attributable to artifacts of the data analysis methodology and/or the representativeness of the survey. For example, $60.08 \%$ of the respondents were over age 55, with $15.21 \%$ over the age of 66 . Thus, there was not equal representation across age groups, which would weaken the ability to detect an age-based trend in attitude. Furthermore, age was analyzed as an ordered categorical variable based on 10-year age ranges, which further undermines the power to detect an effect. Finally, the analysis method (i.e., multiple regression) controlled for the effects of other variables, such as having a PhD, years of experience, and faculty rank. Any informally perceived association between age and acceptance of JD-CPAs as accounting educators might, therefore, be due to the confounding of age and other variables.

\section{Conclusion}

CARDWELL, CARDWELL, NORRIS, \& FORREST / DOI: 10.5929/9.1.3 
The research shows that there is currently a meaningful presence of JD-CPAs in accounting faculties in AACSB research schools as well as ACBSP teaching schools, all of which are accredited by SACS. Respondents PhDs at research schools with PhDs were substantially less likely to recommend hiring a JDCPA as an alternative to $\mathrm{PhD}$ in accounting other than for teaching tax- and business law-related courses. However, as for the teaching schools with only SACS accreditation and balanced schools with programmatic accreditation by ACBSP, there was a considerable degree of favorable inclination to recommend the hiring of JD-CPA candidates when the hiring of a candidate with a PhD in accounting is infeasible due to the shortage of PhDs in accounting and the high market value of such candidates.

There are no explicitly stated limits to the number of JD-CPAs that can be hired within an accredited program (AACSB, 2017b; ACBSP, 2016; SACS, 2012). Accordingly, academic deans, department chairs, and faculty search committees could ameliorate the problematic shortage of accounting PhDs in the academic marketplace by increasing their targeted efforts to recruit and hire JD-CPA credentialed candidates for the available positions in accounting education, especially at non-AACSB accredited schools, which comprise approximately $69 \%$ of North American 4-year colleges and universities (AASCB, 2017a, p. 50). Whatever the institutional orientation may be, there appears to be a substantial need for additional research on alternative remedies to inform deans and others involved in the search for accounting faculty about other realistic and reasonable opportunities to replace their retiring accounting faculty members in the era when there is a substantial shortage of PhDs in accounting in the academic marketplace.

\section{Limitations and Future Research Directions}

To ensure the anonymity of survey respondents, no information was collected concerning institutional affiliation, making it impossible to tell how many responses were received from employees of the same institution. Future research could explore innovative methods of matching responses from the same school without compromising anonymity. Additionally, the survey should be replicated outside of the SACS accreditation region. Additional insight into the roles of JD-CPAs in departments of accounting could also be gained by surveying only JD-CPA accounting educators on topics specific to their experiences.

Other topics for future research could include: 1 ) how the hiring of additional JD-CPAs impacts actual learning in accounting programs by reference to performance on CPA exams or other assessment data, 2) whether or not employers will recruit differently from programs with more professionally oriented JDCPA faculty members, 3) whether accounting programs with higher concentrations of professionally oriented JD-CPA faculty members will be perceived as lower-quality, and 4) further analysis of the results of surveys conducted by the Pathways Commission relating to acceptance of professionally-oriented faculty and practitioner-oriented research within the academic community.

\section{References}

Accreditation Council for Business Schools and Programs. (2016). ACBSP Standards and Criteria for Demonstrating Excellence in Baccalaureate/Graduate Degree Schools and Programs. Retrieved from https://c.ymcdn.com/sites/www.acbsp.org/resource/collection/ EB5F486D-441E-4156-999100D6C3A44ED1/ACBSP Standards and Criteria - Bacc-Grad.pdf

Akaike, H. (1974). A new look at the statistical model identification. IEEE Transactions on Automatic Control, 19, 716-723.

American Academy of Attorney-CPAs. (2017). Connect. Retrieved July 23, 2017, from https://www.attorney-cpa.com/connect/

American Accounting Association. (2017). Thinking of a PhD? Retrieved from 
http://aaahq.org/Education/Thinking-of-a-PhD/School-List\#ae

American Bar Association. (2013). Standards and Rules of Procedure for Approval of Law Schools. Retrieved from https://www.americanbar.org/content/dam/aba/publications/misc/ legal education/Standards/2012 2013 aba standards and rules.authcheckdam.pdf

American Bar Association. (2015). Lawyer Demographics. Retrieved from https://www.americanbar.org/content/dam/aba/administrative/market research/lawyerdemographics-tables-2015.authcheckdam.pdf

Association to Advance Collegiate Schools of Business. (2017a). Business School Data Guide. Retrieved from http://www.aacsb.edu/-/media/aacsb/publications/data-trends-booklet/2017.ashx?la=en

Association to Advance Collegiate Schools of Business, (2017b). Eligibility Procedures and Accreditation Standards for Business Accreditation. Retrieved from http://www.aacsb.edu/Lmedia/aacsb/docs/accreditation/standards/business-2017-update.ashx?la=en

Bailey, C. D., Hermanson, D. R., \& Louwers, T. J. (2008). An examination of the peer review process in accounting journals. Journal of Accounting Education, 26(2), 55-72.

Bishop, C. C., Boyle, D. M., Carpenter, B. W., \& Hermanson, D. R. (2016). Transitioning into academia: A new pathway for practitioners. Journal of Accountancy, 221(3), 48-53.

Blanthorne, C., Kovar, S. E., \& Fisher, D. G. (2007). Accounting educators' opinions about ethics in the curriculum: An extensive view. Issues in Accounting Education, 22, 355-390.

Boyle, D. M., Carpenter, B. W., \& Hermanson, D. R. (2015). The Accounting Faculty Shortage: Causes and Contemporary Solutions. Accounting Horizons, 29(2), 245-264.

Hasselback, J. (2014). Accounting Faculty Directory 2014-2015. Upper Saddle River, NJ: Prentice Hall.

Hasselback, J., (2016). Accounting Faculty Directory 2016-2017. Upper Saddle River, NJ: Prentice Hall.

Hunt, S. C., \& Jones, K. T. (2015). Recruitment and Selection of Accounting Faculty in a Difficult Market. Global Perspectives on Accounting Education, 12, 23-51.

National Science Foundation, National Center for Science and Engineering Statistics. (2016). Doctorate Recipients from U.S. Universities: 2015. Special Report NSF 17-306. Arlington, VA. Available at www.nsf.gov/statistics/2017/nsf17306/

Prather-Kinsey, J., Savage, A., Boyar, S., \& Exline, J. (2018). A call to practitioners: You can play a bigger role in academia and share your experience with accounting students who are hungry for real-world knowledge. Strategic Finance, 100(2), 54-60.

Prescott, G. L., Noland, T. G., \& Vann, C. E. (2017). Universities need you! Strategic Finance, (April), 46-53.

Ruff, M., Thibodeau, J. C., \& Bedard, J. C. (2009). A profession's response to a looming shortage: Closing the gap in the supply of accounting faculty. Journal of Accountancy, 207(3), 36-40.

Schneider, G. P., \& Sheikh, A. (2012). Addressing the shortage of accounting faculty: Using non-tenuretrack positions. Academy of Educational Leadership Journal, 16(1), 1-18.

Shipley, K., \& Engle, R. (1982). We need more PhDs in accounting. Management Accounting 54(5), 36-40.

Showalter, D. S., \& Bodtke, J. (2017). How to effectively integrate professionally oriented faculty to achieve the department's mission. Issues in Accounting Education, 32, 39-46. 
Southern Association of Colleges and School Commission on Colleges. (2006). Faculty Credentials Guidelines. Retrieved from http://www.sacscoc.org/pdf/081705/faculty\%20credentials.pdf

Southern Association of Colleges and School Commission on Colleges. (2012, $5^{\text {th }}$ ed.). The Principles of Accreditation: Foundations for Quality Enhancement. Retrieved from http://www.sacscoc.org/pdf/2012PrinciplesOfAcreditation.pdf

Stone, W. E. (1974). The accounting PhD Marketplace--Updated 1974-1975. Journal of Accountancy, 138, 104. (cited in Shipley and Engle, 1982)

The Pathways Commission. (2012). Charting a National Strategy for the Next Generation of Accountants. Retrieved from http://maaw.info/ArticleSummaries/ArtSumPathwaysCommissionReport.htm

The Pathways Commission. (2015). Implementing the Recommendations of The Pathways Commission: Year Three. Retrieved from commons.aaahq.org/files/f8b68c89a0/Pathways2015Report.pdf

Tukey, J. (1949). Comparing individual means in analysis of variance. Biometrics, 5(2), 99-114.

\section{About the Authors}

Ramsey L. Cardwell (rlcardwe@uncg.edu) is currently a Ph.D. candidate in the Department of Educational Research Methodology at the University of North Carolina at Greensboro. He has a wide array of methodological and substantive interests, including survey research methodology, standardized test equating, and propensity score matching. Ramsey has collaborated with scholars from other fields such as accounting and linguistics on survey-based research projects and has presented at regional, national, and international research conferences such as the National Council on Measurement in Education (NCME) and the Asian Association for Language Assessment (AALA) annual conferences.

Ronald O. Cardwell (cardwellro@guilford.edu) is currently an Assistant Professor of Accounting at Guilford College. He has over twenty-five years of professional practice as a Certified Public Accountant and attorney and has thirteen years of experience teaching financial accounting, tax accounting, and business law.

John T. Norris, Jr. (jnorris@uiwtx.edu) is currently an Associate Professor of Accounting and the Director of the Master of Science in Accounting degree program at the University of the Incarnate Word (Texas). His accounting career includes 25 years in the aerospace industry as an Assistant Controller, Controller, Director of Finance, and Chief Financial Officer.

Michael P. Forrest (mforrest@uiwtx.edu) is currently Professor of Business Law at the University of the Incarnate Word (Texas). His early legal career includes experience as a law clerk on the lowa Supreme Court and 10 years as a trial attorney. 